\title{
Struggles for recognition: a content analysis of messages posted on the Internet
}

This article was published in the following Dove Press journal:

Journal of Multidisciplinary Healthcare

3 July 2012

Number of times this article has been viewed

\author{
Anders Johan W \\ Andersen ${ }^{1,2}$ \\ Tommy Svensson ${ }^{3}$ \\ 'Department of Psychosocial Health, \\ University of Agder, Norway; ${ }^{2}$ Nordic \\ School of Public Health, Gothenburg, \\ Sweden; ${ }^{3}$ Department of Behavioral \\ Sciences and Learning, Linköping \\ University, Linköping, Sweden
}

Background: The Internet has enlarged the possibilities of human communication and opened new ways of exploring perceptions of mental health. This study is part of a research project aiming to explore, describe, and analyze different discourses of mental health in Norway and Sweden, using material from Internet-based services.

Aim: To examine messages posed by users of publicly available question-and-answer services and to describe their content.

Methods: A Web search was used to identify Norwegian and Swedish Websites offering mental health services by email or posted messages. A total of 601 messages from 20 services, 10 Norwegian and 10 Swedish, were analyzed by means of qualitative content analysis and further interpreted in light of the social theory of recognition by Honneth.

Results: Eight categories emerged from the analysis: family life, couples, others, violence, the ungovernable, self-image, negotiating normality, and life struggles. These categories were then grouped into three themes: (1) relationship to significant others, (2) relationship to self, and (3) relationship to the social community. The themes promoted an understanding of mental health as closely connected to political and social factors.

Conclusions: The results showed a variety of concerns from various parts of life and empowered the view that mental health should be understood broadly, at a conceptual level. Mental health emerged as a deeply relational concept that emphasized the equal distribution of chances in life. It strengthened the moral grammar of social inclusion and the acceptance of plurality in social life.

Keywords: Internet-based services, mental health, public health, social theory

\section{Introduction}

Questions regarding mental health represent major challenges to public health in Scandinavia ${ }^{1}$ and the rest of the western world. ${ }^{2,3}$ However, the ways of understanding these phenomena vary ${ }^{4,5}$ and seem to be culturally negotiated ${ }^{6,7}$ and are, in many cases, historically transient. ${ }^{8,9}$ History teaches us that what may appear as truths about the limited capacities of population subgroups at one point in time may later be revealed as unfounded assumptions. ${ }^{10}$ The emergence of a holistic concept of health and visions of greater emphasis on health promotion than on disease prevention have led the World Health Organization ${ }^{3,11}$ and the European Union ${ }^{12}$ to emphasize a broader concept of mental health that is even more dependent upon political and social factors than concepts of mental illness. Mental health emerges as a socially negotiable and timely situated human phenomenon. However, during the last two decades, health authorities have been criticized for promoting an uncritical and individualized 
healthism that locates deficiencies and problems, mainly within individuals. ${ }^{13-15}$

The Internet has created new methods of human communication that are valued for their convenience, low cost, and opportunities for anonymity. ${ }^{16}$ Researchers argue that Internet-based mental health services have the capacity to change the way people seek and get help. ${ }^{17,18}$ Accordingly, it is of interest to examine these services in order to extract some meaning from the submitters' messages and bring them back to society for reflection and discussion. What questions are posted by the users of such services? How might the content be interpreted, and how might these interpretations inform the societies in which they emerge? These questions are discussed in this article. The study promotes a bottom-up perspective in research, using the messages of the service users on Internet-based services as a basis to reflect upon social development and public health policy. It is part of a research project aiming to explore, describe, and analyze different discourses of mental health in Norway and Sweden, using material from Internet-based services. ${ }^{19}$

Although such Internet services contain unique texts written in unique contexts, several services claim authority as spokesmen for the citizenry toward the government, highlighting the different challenges that people face in everyday life. In fact, the Internet services present the communication not only as information for possible service users, but also as publicly available information that amplifies the challenges people face in everyday life. The information might be compared with patient information leaflets. ${ }^{20}$ In this study, we used messages posted on Internet-based services in Norway and Sweden as an entry to explore perceptions of mental health. The study aims to examine messages posed by users of publicly available question-and-answer services and to describe their content.

\section{Method}

\section{Data collection and material}

In 2009, we systematically mapped existing Websites published in Norwegian and Swedish, using keywords inspired by two recognized national email services. The Norwegian keywords were "psykisk helse" (mental health), combined with either "meldingstjeneste" (message service), "svartjeneste" (answering service), or "mailtjeneste" (email service). The Swedish keywords were "psykisk hälsa" (mental health), combined with "nättjänst" (Web service), "mailtjänst" (email service), "mejltjänst” (email service), "mail nätforum" (email web forum), "chatte mail forum" (chat email forum), or "jourmail” (emergency mail). The search engines used in this mapping were Google and Kvasir. The search yielded 502 hits. After briefly reviewing the hits, we narrowed the scope of our search by excluding irrelevant sites. Snowball sampling (ie, including references and recommendations to other Websites mentioned on relevant sites) increased the sample. ${ }^{21}$ The intention was to be as openminded as possible in the sampling process and include all Websites offering mental health services by email or posted messages. At the completion of this review process, our sample included 28 Norwegian and 32 Swedish Websites. In a preliminary study, these Websites were analyzed in order to explore their characteristics, and hence, highlight origin, target groups, counselor qualifications, and major themes. ${ }^{19}$

The present study examined the content of messages posted by the users of these Internet-based services in Norway and Sweden. We included Websites with easily accessible services; the communication between the service users and the services were open to all readers and publicly available. The services did not demand any type of membership, and the messages were presented as being written by the service users themselves and not edited by the services. Moreover, it was important that the submitters were informed of this publishing policy on the Website. Using these inclusion criteria, we ended up with a sample of 20 Websites: 10 Norwegian and 10 Swedish.

Four of the services were privately owned and run, five were initiated and delivered by nongovernmental organizations, and eleven Websites were publicly owned and driven. Although our first study showed that Internet-based services offer slightly varied tools to reach out to the public, ${ }^{19}$ the services included in this study used question-and-answer tools. The submitters' questions were answered mainly by educated professionals; by some services described as psychologists, school nurses, family therapists, and/or social workers; and by others just referred to as professionals or experts. Two services described the responders only as "grown-ups," while two others also supplied answers from former service users. The submitters in this study were anonymous; therefore, it is impossible to trace their identities. After reading all the messages, it was our impression that each message was written by a different person. Approximately half of the services limited the target group according to age, addressing users aged between 10 and 30 years. The remaining services specified no target groups and were open to everyone.

The included services had different profiles, and they categorized the messages they received from service users differently. The sampling strategy was consistent in the sense 
that only material regarded to be of relevance to mental health by the services was collected. The same variation was noticeable regarding the number of messages: some Websites had a few messages published, compared to others that had hundreds. We limited the sample by selecting up to 50 most recent messages. All messages were collected between October 2010 and June 2011. The data for this study consisted of 601 different messages, ranging from five to almost 3000 words, and totaling about 150 pages.

\section{Ethical considerations}

Given the openness and availability of Websites to the public, as well as their anonymous nature and privacy policies, we judged it ethically acceptable to perform an analysis of the communication without seeking informed consent from the submitters or the services. This way of collecting data material from the Internet was approved by the National Committee for Research Ethics. They did not require licensing or special ethical approval as long as (1) the information was collected from services otherwise publicly available and (2) the services provided technical solutions that offered the submitters total anonymity. This method of collecting data material is similar to other studies ${ }^{22}$ and supported in textbooks on methodology. ${ }^{23}$

\section{Qualitative content analysis}

Qualitative content analysis might be described as the bridge between the original text and the presented results. ${ }^{24}$ It consists of a slow and systematic transformation of the original text into condensed categories and themes of meaning. According to Graneheim and Lundman, ${ }^{25}$ creating categories is the core feature of qualitative content analysis. The analytical process was initially characterized by reading and rereading the messages to achieve an in-depth familiarity with the text. ${ }^{26}$ The reading was characterized by a backand-forth movement between the whole and parts of the text and was characteristic of the entire analytical process. ${ }^{25}$ It shows familiarity with the process of understanding a text hermeneutically. ${ }^{27}$

Qualitative content analysis deals with interpretation of texts. However, the interpretations might vary in depth and levels of abstraction. Graneheim and Lundman ${ }^{25}$ distinguished between two levels of content: manifest content and latent content. Manifest content refers to what the text says and refers to a process of shortening the volume of the text without reducing its variation of meaning. Latent content deals with the relationship aspect and involves an interpretation of the underlying meaning of the text. ${ }^{25}$ We conducted analyses of both the manifest and latent content of the data material.

\section{Analyzing the manifest content}

After gathering the messages into a common document, we shortened the text and condensed the meaning. The text was further processed and transformed in a way that highlighted the service users' concerns in relation to questions of mental health. This led to the construction of some subcategories. Each message could have up to three different subcategories. We then read the subcategories and compared them to the original messages, adjusting some slightly to maintain a reasonable likeness between the original text and the subcategories. During this process, some of the subcategories were merged, slightly reducing the total number. The subcategories were then aggregated with similar subcategories, thus making it possible to trace major categories among the subcategories. Eight categories emerged in this process, and they captured the main empirical interpretations of the manifest content.

\section{Analyzing the latent content}

The analysis of the manifest content revealed some threads of meaning across the categories and even manifested some inherent preconditions in the messages. The process led us to some reflection of the underlying meaning of the content derived from the manifest content, which might be described as an inductive analysis of the latent content. We assembled the categories into three themes that served as empirical interpretations of the latent content in the material. The analysis of the manifest content and the inductive analysis of the latent content are illustrated in Table 1.

At the conclusion of the empirical analysis of the latent content, it became suitable to supply the interpretation with a theoretical analysis of the latent content. This might be described as a deductive analysis of the latent content that enabled a dialogue between the empirical results and a theoretical reference. While working with this study, we found a similarity between the service users' concerns and the social theory of recognition developed by the German philosopher Axel Honneth. ${ }^{28,29}$ His theory offers a way to deepen the understanding of the latent content. This way of introducing theoretical reflections upon empirical interpretations is inspired by the reflexive methodology of Alvesson and Sköldberg. ${ }^{27}$

Theoretical background: the social theory of recognition The social theory of recognition is regarded as one of Axel Honneth's main scientific contributions to date. ${ }^{28,29}$ 
Table I Illustration of the inductive analyzing process used to explore the manifest and latent content of the messages from submitters on Internet-based mental health services in Norway and Sweden

\begin{tabular}{llll}
\hline Original text & Condensed text & Subcategory & Category \\
\hline Hi, l'm so very scared because my mom beats me & A submitter beaten by his/her & Beating & Violence \\
$\begin{array}{l}\text { and my little siblings. I don't know what to do or } \\
\text { anything like that. I feel too scared to do anything }\end{array}$ & mother. Afraid and doesn't & know what to do \\
\hline
\end{tabular}

The theory was influenced by the early social philosophical works of Hegel and developed in close dialogue with the social psychology of Mead, the communicative ethics of Habermas, and the object relation theory of Winnicott. The study suggests deepening the understanding of the submitters' concerns in relation to this concept of recognition.

According to Honneth, ${ }^{29}$ human flourishing and personal well-being result from intersubjective processes wherein the question of mutual recognition is vitally important to the development of personhood. ${ }^{14}$ Honneth's ${ }^{28,29}$ social theory distinguishes among three forms of reciprocal recognition. Moreover, each form of recognition has a corresponding level of misrecognition, with consequences on both individual and societal levels. ${ }^{30}$

First, he emphasizes the importance of love relationships, understood here as emotional attachments among a small number of people, including friendship, erotic relationships between lovers, and the parent-child relationship. He points out that reciprocal recognition in such relationships encompasses the establishment of basic self-confidence. ${ }^{28,29}$

Second, Honneth considers each person a responsible, autonomous agent in his/her own life, possessing the claim to the moral rights and responsibilities of a full legal person within our own communities. ${ }^{28,29}$ This relationship emphasizes the legal rights of each citizen. Accordingly, recognition as a person who is entitled to the same status and treatment as every other person is vital to the development and maintenance of self-respect.

The last type of relationship connects with the extent to which every citizen is included as a unique and irreplaceable member of the social community. It challenges questions of solidarity and the cultural struggle for the cultural climate in which the acquisition of self-esteem has become broadly possible. $^{29,31}$

\section{Results}

This section is divided into two parts: first, the results from the analysis of the manifest content and second, the results from the analysis of the latent content. However, the relations between the subcategories, categories, and themes are briefly summarized in Table 2.

\section{The manifest content of the submitters' messages}

This section presents eight major categories and 27 subcategories that emerged from the analysis of the manifest content.

\section{Family Life}

Life at home was a major category, and it included the various relationships within a household, but not issues related to couples. Many messages referred to tensions between family members and frequently were related to questions of

Table 2 Service users' concerns voiced on Internet-based mental health services in Norway and Sweden

\begin{tabular}{|c|c|c|}
\hline Subcategories & Categories & Themes \\
\hline I. Conflicts & I. Family life & $\begin{array}{l}\text { Relationship to } \\
\text { significant others }\end{array}$ \\
\hline \multicolumn{3}{|l|}{ 2. Deaths } \\
\hline \multicolumn{3}{|l|}{ 3. Divorce } \\
\hline $\begin{array}{l}\text { 4. Alcohol abuse, drug } \\
\text { addiction, and mental } \\
\text { disorders }\end{array}$ & & \\
\hline 5. Falling in love & 2. Couples & \\
\hline \multicolumn{3}{|l|}{ 6. Serious relationships } \\
\hline \multicolumn{3}{|l|}{ 7. Breaking up } \\
\hline 8. Friends & 3. Others & \\
\hline \multicolumn{3}{|l|}{ 9. Helpers } \\
\hline \multicolumn{3}{|l|}{ 10. School } \\
\hline II. Beating & 4. Violence & \\
\hline \multicolumn{3}{|l|}{ 12. Sexual abuse } \\
\hline \multicolumn{3}{|l|}{ 13. Harassment } \\
\hline \multicolumn{3}{|l|}{ I4. Bullying } \\
\hline I5. Emotions & 5. The ungovernable & Relationship to self \\
\hline \multicolumn{3}{|l|}{ 16. Thoughts } \\
\hline \multicolumn{3}{|l|}{ 17. Actions } \\
\hline 18. Looks and appearance & 6. Self-image & \\
\hline \multicolumn{3}{|l|}{ 19. Self-respect } \\
\hline \multicolumn{3}{|l|}{ 20. Social anxiety } \\
\hline 21. Difficult changes & $\begin{array}{l}\text { 7. Negotiating } \\
\text { normality }\end{array}$ & $\begin{array}{l}\text { Relationship to the } \\
\text { social community }\end{array}$ \\
\hline \multicolumn{3}{|l|}{$\begin{array}{l}\text { 22. Bodily function and } \\
\text { malfunction }\end{array}$} \\
\hline \multicolumn{3}{|l|}{$\begin{array}{l}\text { 23. Eating, weight, and } \\
\text { exercise }\end{array}$} \\
\hline \multicolumn{3}{|l|}{ 24. The art of classification } \\
\hline 25. Depression and despair & 8. Life struggles & \\
\hline \multicolumn{3}{|l|}{ 26. Deadlocked situations } \\
\hline 27. Negotiating death & & \\
\hline
\end{tabular}


independence, self-determination, and growing up. Many service users reflected on the stressful consequences of nagging, quarrelling, and conflicts. Others described concrete events, including a death in the family - the submitters were concerned about dealing with personal loss and handling the grief process within the family. Another subcategory involved the practical and emotional difficulties that impact a family during and after a divorce. Finally, some questions focused on the health of family members. Some service users asked for help in interpreting events in their daily life to clarify the severity of a situation. However, most messages in this subcategory contained questions about handling a family member with alcohol, drug, or mental health problems:

I'm so confused ... don't know how I am but I feel bad for my mum. She is mentally ill and I do not know how to handle the situation .... Sometimes, she is completely normal, but then again she might start walking around talking to herself. She hears voices and screams at them.

\section{Couples}

Several service users asked questions about establishing, maintaining, or ending relationships. The first subcategory, falling in love, included messages that asked how to behave, what to say, and how to dress on a date. The service users were united in their efforts to be liked and, ultimately, to become someone's boyfriend/girlfriend. The next subcategory focused on experiences gained from serious relationships. The messages highlighted various aspects of living together in serious relationships and raised questions about proximity and the need to be loved; differences in sexual needs; (un)wanted dreams of other partners; unfaithfulness and adultery; dependency; pregnancy and abortion; quarrelling and conflicts; jealousy and the need to control; relationships with in-laws; and relationships with former lovers. Many service users expressed concern about their partners' (mis)use of medicines, drugs, and alcohol and worried about their health. Others referred to their lovers' difficult moods and showed both a fear of losing them and a wish for a breakup. The final subcategory focused on breaking out of relationships contained messages showing a sort of negotiation phase that included questions such as

- Should I break up?

- Can I stand this anymore?

- How can I end this in a respectful manner?

Others were confused and asked for help in understanding a break-up. Some reported their sense of loss and longing for an expartner, whereas other messages posed questions regarding threats of suicide and severe trouble with expartners.

\section{Others}

Friendship emerged as an important subcategory, and many messages raised questions about how to get and keep a friend. Some submitters longed for a soul mate:

Hello. I have tried to find some kind of association or similar where you can join and meet others who feel miserable.

I really, really need to meet others who are like me. Where should I go?

Others mostly sought answers about how to maintain friendships, settle conflicts, and deal with losses. Service users expressed concerns about their friends and wanted to be helpful.

Another aspect was the question of helpers. Some submitters wanted to establish contact with professionals but were concerned about confidentiality within the services, especially whether the helpers were obliged to inform parents. Some sought information about their right of access to social services, and others were more concerned about various forms of treatment:

I have a son aged 10 with severe obsessions and compulsions.

How early can he be treated with medication, and what medicines might be appropriate?

A third subcategory involved experiences at school and questions about education. Some service users expressed dissatisfaction with school and others sought direction about career choices.

\section{Violence}

Several submitters reported violation towards either themselves or others: “Hi, I'm so very scared because my mom beats me and my little siblings." This message illustrates the first subcategory in this major theme: service users report some sort of physical violence. Another subcategory focused on rape, sexual assault, and incest, and might be united in the term 'sexual abuse.' A third subcategory involved psychological violence or harassment by persons who telephoned to threaten violence or sent text messages or emails. Bullying or social violation formed a fourth subcategory. Several service users described a lack of acknowledgement and reported bullying for their sexual orientation. Most reported bullying at school. Many submitters received no help from teachers or other authority figures and were very desperate in their struggle for help:

Hi, how can you find happiness in life again? I have been tracked for 6 years which is half my life, and it starts rolling to a close, I've been called emo-gay and so on because I 
listen to sad rap, I get beaten every week, plus I have stopped eating, I lie sleepless in the week, do not know what to do (...) the teachers don't care at school, and I have no real friends because I have been told that they're talking shit about me (...).

\section{The ungovernable}

Loss of control defined another major category. Messages related common stories of being unwillingly subjected to certain emotions, thoughts, and actions without the capacity to govern them. Service users reported lack of control over their feelings and reported uncontrolled emotions such as anxiety, fear, anger, grief, phobias, and love. Most often, they asked for help in gaining control over their feelings:

I get easily angry or sad and when I first start to cry I can't stop! Mom says I should try to keep it inside, but when I do I cry more next time. Can you help me?

Submitters also worried about obsessive thoughts and ideas:

It is the thoughts. They govern me. (...) My thoughts can control themselves without my participation. (...) It's so confusing.

The last subcategory related to actions and mostly posed questions about self-inflicted harm:

I can't stop scratching myself. I have done this for many years and it just gets worse. I really want to quit because the problem interferes with my social life.(...) I can't describe how grateful I would be if I could get help to take control of myself (...)

Lack of control made people ashamed of themselves.

\section{Self-image}

"Hello! I have a big problem; I really don't know who I want to be." This message might serve as an illustration for the next major category presented here. One aspect related to appearance; service users were highly concerned about their own appearance and body, and they monitored their body very closely and critically:

I feel physically ill because of my thighs and my butt. I can't look at myself in the mirror. The only thing I can think of is fat.

Another subcategory related to self-respect. Several messages told stories of people who had trouble liking themselves, some described the hatred they felt towards themselves, and others described themselves as bad persons who were ashamed of their own behavior. Self-image made their daily lives difficult. This was often related to sexuality. Another aspect of this category might relate to the ability to represent oneself in different situations. Many messages told stories of shyness and social anxiety, often describing self-imposed silence, lies, and crippling modesty:

I've worked where I now work for 3 years, but I have not got acquainted with anyone there. And they don't know me. I have no idea why I am this way. If I'm in the same room with 1 or 2 people, it goes smoothly. But should I talk to several people in the room it is just nonsense. I'm probably perceived as fairly daft and false, since I speak in some contexts and not in others, seemingly unrelated.

\section{Negotiating normality}

It might seem strange to distinguish normality as a separate category in this study. Independently of the category in question, messages somehow related to the discourse of normality. However, some messages were more outspoken about the negotiations of normality. One subcategory was related to unwanted changes in mood and lifestyle and a feeling that things had changed for the worse:

To put it shortly, my ability to cope with things is greatly reduced, and things that before would get me in a good mood now create discomfort and headaches. (...)

Other messages told stories of "before and now," of becoming a stranger in life: submitters asked for help in interpreting changes and retrieving the person they once were.

Another subcategory involved function and malfunction. People wondered whether their body functioned normally and expressed concern about irregularities and diseases. Such messages were often related to the genitals and sexuality. People wanted to affirm that their bodies (and sometimes their sexual behavior) were normal. Another important part of these messages involved questions about the effects of prescribed medicines and illegal drugs.

People's relationship to exercise, eating, and weight emerged as another subcategory. Some service users declared that they had an eating disorder, while others negotiated the borders of normality by asking the services for their opinion:

Every time I read a newspaper, I see clothes you might buy in order to look slimmer, food to eat to lose weight, exercises you can do to become more physically fit. It makes me crazy. It feels like I'm dragged into this whole quest 
to be thin (...) I've started to put my fingers in my throat

to throw up ... does this mean I have an eating disorder or am I just weird in some way?

Internet services were often asked to tread a path between normality and deviance. In fact, several submitters posed questions of psychiatric diagnosis: service users wondered if they or others had or might obtain a psychiatric diagnosis. Others lacked information about a diagnosis, pointed to problems with certain diagnoses, or raised questions about incorrect diagnoses. The messages were united in their need for clarification about recognizing when something feels wrong.

\section{Life struggles}

One service user put into words aspects regarding peoples' experiences of living in a social community:

I don't know why I write this ... perhaps because I want somebody to know of my existence ... without them knowing who I am.

Some messages in this group displayed a common description about a lack of love and a feeling of not belonging in the world, recounting unhappy lives, loneliness with or without close friends, incomprehensible despair, and hopelessness. For these submitters, nothing seemed to fit:

I do not know what I am. Depressed, sad or just unhappy.

One thing is certain, I'm not happy.

Submitters often used the word depression, a subcategory in this material.

Others described a deep fear of life, lack of work, longterm strains, and lives on hold or situations where several aspects of life were out of order. It might be a mother whose baby cries all day while the father works and, as such, is clearly situated in time. Others seemed more unrestricted but reported sleeplessness, unemployment, poverty, and a sense of being stuck in life. Many related some sort of misery: personal failure or being in stuck in deadlocked situations.

Hi! I am a man of 28. I'm struggling with anxiety and depression, living by myself and unemployed. I'm struggling with thoughts (some obsessive) of despair, loneliness, sadness, grief, blue mood, too little energy and motivation to do things. I feel that my life is on hold. (...)

Several messages raised the issue of death, which forms a third subcategory. Some service users questioned the meaning of life and had problems seeing life as worthwhile.
Others were tired of an unfriendly world, felt overloaded, and longed for some kind of empty space. They wrote about thoughts of suicide and some reported suicide attempts. Some messages presented this issue almost superficially, whereas others discussed it more thoroughly and sometimes pleaded for help. Others were deeply concerned about friends or family members, fearing for someone's life and wondering what to do about it.

\section{The latent content of the submitters' messages}

Although the manifest content shows a variety of concerns from different parts of life, we suggest the possibility of detecting some threads of meaning across the main categories. The results from the inductive analysis of the latent content are collected into three themes.

\section{Relationship to significant others}

Most concerns voiced by users of Internet-based mental health services related to primary relationships (family life, couples, others, violence). Mental health likely depends upon personal and affectionate relationships with other people.

\section{Relationship to self}

Two categories (the ungovernable, self-image) clearly relate to the service users' relationships towards themselves, focusing on questions of autonomy, self-control, and self-image.

\section{Relationship to the social community}

The last two categories (negotiating normality, life struggles) likely deal with questions of relationship to the community at large, raising questions of normality, deviance, and the struggle to be human.

The proposal of three themes as an inductive analysis of the latent content may be deepened by Honneth's social theory of recognition. ${ }^{28,29}$ His way of distinguishing among the three levels of recognition has apparent similarities with the three themes that emerged from the empirical analysis of the latent content in our study. Of course, the comparison is not totally perfect. Sometimes the concerns of service users affect more than the elements in Honneth's theory; sometimes it is the other way around. Inspired by his social theory, the analysis nevertheless suggests that perceptions of mental health depend crucially upon reciprocal recognition and the development of self-confidence, self-respect, and self-esteem. Furthermore, these modes of practical relationship with oneself can only be acquired and maintained between people (Table 3). 
Table 3 Service users' concerns as voiced on Internet-based mental health services, related to core aspects of the social theory of Axel Honneth

\begin{tabular}{lll}
\hline $\begin{array}{l}\text { Service users' } \\
\text { concerns }\end{array}$ & Form of recognition & $\begin{array}{l}\text { Practical relation } \\
\text { to self }\end{array}$ \\
\hline $\begin{array}{l}\text { Relationship to } \\
\text { significant others }\end{array}$ & Love & Basic self-confidence \\
$\begin{array}{l}\text { Relationship to self } \\
\text { Relationship to the } \\
\text { social community }\end{array}$ & $\begin{array}{l}\text { Legal order } \\
\text { Solidarity }\end{array}$ & $\begin{array}{l}\text { Self-respect } \\
\text { Self-esteem }\end{array}$ \\
\hline
\end{tabular}

Honneth describes struggles for recognition as struggles for recognition of the value each person ascribes to him- or herself within the family, the order of justice, and the general society. ${ }^{28,29}$ Historically, these relationships of recognition are not given; rather, they depend on a constant social struggle that includes the fair distribution of material goods, equal opportunities, cultural acceptance, and social inclusion. ${ }^{32}$ Consequently, the understanding of mental health as it is preserved at Internet-based services in Norway and Sweden seems closely related to the struggle for recognition and, as such, represents a moral grammar of inclusion and solidarity within society and the maintenance of basic human rights. It emerges as a clearly relational concept.

\section{Discussion}

Service users' concerns about Internet-based mental health services in Norway and Sweden vary and accommodate diverse phenomena and living conditions. The manifest content of the submitters' messages suggest that the concept of mental health requires broad interpretation. Furthermore, in order to respond adequately to the concerns of each individual, it seems reasonable to argue for the development and maintenance of ecologies of practices in public health. ${ }^{14}$ It seems important to strengthen the ability for such practices to tailor their services to both the concrete situation and the specific needs and requests of each individual.

However, this might locate concerns and problems mainly within individuals, thus weakening one of the most important finding from the analysis of the latent content of the submitters' messages. These results emphasize the relational nature of mental health and show that service users are dependent on others to flourish as human beings and maintain good mental health. In fact, the scope of mental health seems dependent upon preconditions not immediately available to subjects themselves, particularly if they individualize their concerns too much. ${ }^{28}$

The theoretical analysis of the latent content and Honneth's concept of recognition increases clarity in this regard and shows how mental health is dependent on social and political factors. From the perspective of health policy, this is important. It seems reasonable to develop and maintain services that are tailored at an individual level; at the policy level, it is even more important to emphasize the social and political aspects of mental health. Our theoretical analysis suggests that the different patterns of recognition represent relational prerequisites, which we have to add in our minds whenever outlining structures of public health policy. ${ }^{29}$

It might be argued that this is not merely valid for the understanding of mental health in a broad public health perspective. In a study that investigated social integration of persons with psychiatric disabilities, Ware et al ${ }^{10}$ argued for the necessity of a re-examination of the ideas underlying existing clinical and service paradigms. They further emphasized the necessity of social change, aiming at connectedness and citizenship for all people. In their study, connectedness far exceeds social support and includes identification with a larger group. Citizenship refers to rights, privileges, and responsibilities enjoyed by members of a democratic society. Their study supports the notion of mental health as a relational concept that emphasizes social equity and justice. This study supports the voices that demand a change of dominating perspective within the mental health field in general. Human flourishing is the envisioned outcome for all people. ${ }^{10,29}$

\section{Methodological considerations}

This study is based on data filtered by the researchers during the sampling process. Although the criteria for inclusion are clearly defined and explained, they also limit the results. The analysis does not consider possible differences inherent in the limitations due to the backgrounds of the service users (eg, age, sex, type of problem) and the services (eg, sector, public messages); such factors might influence the results and weaken the credibility of the study. Furthermore, Internetbased services are not used or evenly distributed among the citizens of Norway and Sweden. The digital divide that emerged as a concept in the mid-1990s refers to the gap between people with access to the Internet and those with limited or no access at all. Exclusionary factors for these new technological developments, including lack of money, knowledge, and other substantial recourses, clearly might limit the external validity of the study.

The first author suggested some initial categories in the analysis. The categories were crosschecked by the second author, and the final categories were decided upon jointly by the two authors. There were no independent, qualitative researchers crosschecking these final categories; this might be 
described as a methodological weakness. Moreover, because some of the categories investigated here might not be mutually exclusive, there is some overlap in this presentation. This can be viewed as a methodological weakness related to the analytic process and the demand for internal homogeneity and external heterogeneity. ${ }^{33}$ However, it might also illustrate the complexity and entanglement that exists within the concept of mental health and underline the importance of a broad and inclusive concept of mental health. This is supported by Graneheim and Lundman, ${ }^{25}$ underlining the intertwined nature of human experiences.

The field of Internet-based research is still young, and it poses challenging questions about autonomy, maleficence, justice, and beneficence. ${ }^{34,35}$ Despite the public availability of messages posted on Internet-based mental health services, the service users are completely masked, making people feel that they can publish information on the Web that they may not want exposed in the long run. To protect the submitters, this study does not reveal the connection between the messages and the services. In addition, because the study is published in English, quotations are less recognizable for the people involved. This is an important consideration in this kind of research, where information from particular moments in life is made more time-resistant and durable and used for other purposes than the submitters might have foreseen. However, this creates a risk of an unintended translator bias, as all the quotations presented to underline the findings were translated into English by the authors. ${ }^{36}$

\section{Conclusion}

This study aimed to explore and describe current perceptions of mental health by analyzing people's concerns in everyday life as they are preserved on Internet-based mental health services in Norway and Sweden. Our results show a variety of concerns that relate in various ways to the struggle for recognition. Mental health emerges as a deeply relational concept, one that requires understanding in the context of political and social conditions that emphasize an equal distribution of chances in life. It strengthens the moral grammar of social inclusion and acceptance of plurality in social life. The study might serve as an invitation to examinations of the service users' expectations toward the Web services, and even more to investigations of the answers given by the Internet-based services.

\section{Acknowledgments}

The project was supported by The Nordic Research Academy in Mental Health at The Nordic School of Public Health. We wish to thank the University of Agder for funding this project. Malvern Lumsden and Karen Williams have been our consultants in questions regarding the English language, and we wish to express our gratitude for their contribution. Moreover, Professor Olle Söderhamn at the University of Agder read drafts of the final manuscript, and we appreciate his comments.

\section{Disclosure}

The authors report no conflicts of interest in this work.

\section{References}

1. Jespersen M, Wahlbeck K, Tvedt J, Suvanto SR, Unnsteinsson H, Fredén L. Strengthening Mental Health in the Nordic Countries Suggestions for Initiatives for Promotion of the Exchange of Knowledge and Experience. Report by the Nordic Expert Group on Mental Health, 2009-2010. Copenhagen, Denmark: Nordic Council of Ministers; 2011.

2. World Health Organization. Integrating Mental Health into Primary Health Care: A global perspective. Geneva, Switzerland: WHO; 2008.

3. Herrman H, Saxena S, Moodie R, Walker L. Introduction. In: World Health Organization. Promoting Mental Health: Concepts, emerging evidence, practice. Geneva, Switzerland: WHO; 2004:2-18.

4. Colombo A, Bendelow G, Fulford B, Williams S. Evaluating the influence of implicit models of mental disorder on processes of shared decision making within community-based multi-disciplinary teams. Soc Sci Med. 2003;56(7):1557-1570.

5. Wakefield JC. The concept of mental disorder. On the boundary between biological facts and social values. Am Psychol. 1992;47(3): 373-388.

6. Wilkinson R, Pickett K. The Spirit Level: Why more equal societies almost always do better. London, UK: Allen Lane; 2009.

7. Waxler NE. Is outcome for schizophrenia better in nonindustrial societies? The case of Sri Lanka. J Nerv Ment Dis. 1979;167(3):144-158.

8. Hacking I. Mad Travelers: Reflections on the Reality of Transient Mental Illnesses. Charlottesville, VA: University Press of Virginia; 1998.

9. Conrad P, Schneider JW. Deviance and Medicalization: From Badness to Sickness. 2nd ed. Philadelphia, PA: Temple University Press; 1992.

10. Ware NC, Hopper K, Tugenberg T, Dickey B, Fisher D. Connectedness and citizenship: redefining social integration. Psychiatr Serv. 2007; 58(4):469-474.

11. World Health Organization. The World Health Report 2001 - Mental Health: New Understanding, New Hope. Geneva, Switzerland: WHO; 2001.

12. European Union. Green Paper. Improving the Mental Health of the Population: Towards a Strategy on Mental Health for the European Union. Brussels, Belgium: Commission of the European Communities; 2005.

13. Andersen AJW. Governing health. Discourse analysis in public health research. In: Salvini A, Andersen AJW, editors. Interactions, Health and Community. Theories and Practices from Italy and Norway. Pisa, Italy: EDIZIONI PLUS, Pisa University Press; 2011:21-34.

14. Fisher P, Owen J. Empowering interventions in health and social care: recognition through 'ecologies of practice.' Soc Sci Med. 2008;67(12): 2063-2071.

15. Petersen A, Lupton D. The New Public Health: Health and Self in the Age of Risk. London, UK: Sage; 1996.

16. Griffiths F, Lindenmeyer A, Powell J, Lowe P, Thorogood M. Why are health care interventions delivered over the internet? A systematic review of the published literature. $J$ Med Internet Res. 2006;8(2):e10.

17. Fukkink RG, Hermanns JM. Children's experiences with chat support and telephone support. J Child Psychol Psychiatry. 2009;50(6):759-766.

18. Ybarra ML, Eaton WW. Internet-based mental health interventions. Ment Health Serv Res. 2005;7(2):75-87. 
19. Andersen AJW, Svensson T. Internet-based mental health services in Norway and Sweden - characteristics and consequences. Adm Policy Ment Health. November 23, 2011 [Epub ahead of print.]

20. Dixon-Woods M. Writing wrongs? An analysis of published discourses about the use of patient information leaflets. Soc Sci Med. 2001;52(9): 1417-1432.

21. Bowling A. Research Methods in Health. Investigating Health and Health Services. 2nd ed. Philadelphia, Pa: Open University Press; 2002.

22. Moncrieff J, Cohen D, Mason JP. The subjective experience of taking antipsychotic medication: a content analysis of Internet data. Acta Psychiatr Scand. 2009;120(2):102-111.

23. Bryman A. Social Research Methods. 3rd ed. New York, NY: Oxford University Press; 2008.

24. Malterud K. Qualitative research: standards, challenges, and guidelines. Lancet. 2001;358(9280):483-488.

25. Graneheim UH, Lundman B. Qualitative content analysis in nursing research: concepts, procedures and measures to achieve trustworthiness. Nurse Educ Today. 2004;24(2):105-112.

26. Tucker I. "This is for Life": A discursive analysis of the dilemmas of constructing diagnostic identities. Forum Qual Soc Res. 2009;10(3): $1-19$.

27. Alvesson M, Sköldberg K. Reflexive Methodology: New Vistas for Qualitative Research. 2nd ed. London, UK: Sage; 2009.

28. Honneth A. Recognition or redistribution? Changing perspectives on the moral order of society. Theory, Culture and Society. 2001;18(2-3): $43-55$.
29. Honneth A. The Struggle for Recognition: The Moral Grammar of Social Conflicts. Cambridge, MA: Polity Press; 1995.

30. Quales van Ufford J. Recognition. A question of morality or professionalism. In: Salvini A, Andersen AJW, editors. Interactions, Health and Community. Theories and Practices from Italy and Norway. Pisa, Italy: EDIZIONI PLUS, Pisa University Press; 2011:47-59.

31. Anderson J. Translator's introduction. In: Honneth A. The Struggle for Recognition: The Moral Grammar of Social Conflicts. Cambridge, MA: Polity Press; 1995:x-xxi.

32. Høilund P, Juul S. Anerkendelse og Dømmekraft $i$ Socialt Arbejde. [Recognition and Judgment in Social Work]/ Copenhagen, Denmark: Reitzel; 2005. Danish.

33. Patton MQ. Qualitative Research and Evaluation Methods. Thousand Oaks, CA: Sage Publications; 2002.

34. Flicker $\mathrm{S}$, Haans D, Skinner H. Ethical dilemmas in research on Internet communities. Qual Health Res. 2004;14(1):124-134.

35. Eysenbach G, Till JE. Ethical issues in qualitative research on internet communities. BMJ. 2001;323(7321):1103-1105.

36. Wiener DB. Betrayal! The 1806 English Translation of Pinel's Traité medico-philosophique sur l'aliénaton mentale ou la manie. Gesnerus. 2000;57:42-50.
Journal of Multidisciplinary Healthcare

\section{Publish your work in this journal}

The Journal of Multidisciplinary Healthcare is an international, peerreviewed open-access journal that aims to represent and publish research in healthcare areas delivered by practitioners of different disciplines. This includes studies and reviews conducted by multidisciplinary teams as well as research which evaluates the results or conduct of such teams or

\section{Dovepress}

healthcare processes in general. The journal covers a wide range of areas and welcomes submission from practitioners at all levels, from all over the world. The manuscript management system is completely online and includes a very quick and fair peer-review system. Visit http://www.dovepress.com/testimonials.php to read real quotes from published authors. 